\title{
Influences on TV Viewing and Online User-shared Video Use: Demographics, Generations, Contextual Age, Media Use, Motivations, and Audience Activity
}

\author{
Beverly A. Bondad-Brown, Ronald E. Rice, and \\ Katy E. Pearce
}

People are increasingly viewing, providing, and recommending video content through the Internet. Applying the uses and gratifications framework, along with contextual age and generational theory, this study identifies and compares motivations for, and their influence on, traditional TV viewing and online user-shared video use among a U.S. sample of adult Internet users. Further, this study explores the form and role of audience activity through online usershared video recommendations (type, channel, and social relation). Overall, the basic U\&G motivations also apply to the new online media world, but differ in levels and influence.

Viewers are increasingly accessing television and video content through the Internet on computers, mobile phones, tablets, and other devices. Television has expanded to include not just viewing scheduled programming, but also using and sharing content, by individuals and groups, via various displays, across multiple time periods, on demand, from many locations, and interactive choice by the viewer/user (Chorianopoulos \& Lekakos, 2008; Spigel \& Olsson, 2004; Strover \& Moner, 2012).

This trend is just one part of the pervasive transformation of media content due to digitization, transmission networks, convergence, relaxation of traditional viewing constraints, and increasing user production of content (Klar, 2011; Rice, 2008).

Beverly A. Bondad-Brown (Ph.D., University of California, Santa Barbara) is an instructional designer with Zeacom, Inc. Her research explores the social and psychological effects of the media, especially pro-social media effects, media enjoyment, and entertainment-education.

Ronald E. Rice (Ph.D., Stanford University) is the Arthur N. Rupe Professor of the Social Effects of Mass Communication in the Department of Communication at University of California, Santa Barbara. His research interests include social aspects of new media, public communication campaigns, network analysis, and organizational communication.

Katy E. Pearce (Ph.D., University of California, Santa Barbara) is assistant professor in the Department of Communication, University of Washington. Her research interests include digital divides and the political use of information and mobile communication technologies and digital content in the transitioning democracies and semi-authoritarian states of the South Caucasus and Central Asia. 
However, little is known about viewers' motivations for accessing online video content in general, the extent to which these are different from traditional TV viewing motivations, and how viewers find out about this content. Thus, this study utilizes the uses and gratifications framework, generational theory, and contextual age, to identify factors influencing online user-shared video use (referred to as OUSV), and how various channels, sources and relationships facilitate sharing among OUSV users.

\section{Online Video}

More general than Internet protocol television or Internet television (Held, 2007; Noam, Groebel, \& Gerbareg, 2004), online video in general refers simply to video content available over the Internet. Online video content providers include major broadcasting networks, local TV stations, large Hollywood film and TV producers, and user-generated content providers. Entire films and TV programs are available for purchase via sites such as iTunes or for streaming via Netflix.com or Hulu Plus, and full-length TV programs are readily available on broadcast network Web sites (e.g., The Office on NBC.com). These same Web sites also offer Web exclusive video clips such as "sneak peeks" of upcoming episodes, deleted scenes from programs, and behind the scenes interviews with cast members. Additionally, television content, as well as amateur video content, can be found on user generated content Web sites such as YouTube. Online video use is by no means a fad. By 2010, the Pew project reported that $71 \%$ of Internet users watched or downloaded video online, up from $33 \%$ in 2006, and $22 \%$ of adult Internet users had uploaded/posted videos online (Moore, 2011; Purcell, 2010). Specifically, this study considers one subset of online video types, which we call "user-shared video," consisting of nonprofessional user-created clips (Ex: funny amateur music videos) or user-provided clips from TV (clip from Saturday Night Live) made available on Internet video sharing Web sites (YouTube or Vimeo).

Advantages to viewing online video content include: A wide variety of content creators; access to content on-demand and multiple times, which creates a more interactive and personalized experience; more targeted, fewer, or no advertisements; access to non-professionally produced content; and the ease of sharing content through online channels. The rise of online video use has created a shift from a passive viewing audience to an active, content-producing and content-sharing audience (Jenkins, 2006; Shirky, 2008). However, there is no centralized "TV guide" available to Internet users, although specific sites may provide "channels" and search tools. Thus, viewers must be able to effectively search, find, and become aware of content, and rely to some extent on recommendations from others. Online video viewing requires a personal computer (PC), mobile phone, or other digital device connected to the Internet, and a broadband connection, which may be costly or simply unavailable for some individuals, especially for older adults (Fox, 2010). Moreover, bandwidth caps on mobile Internet subscriptions may discourage those users from accessing video content. 


\section{Conceptual Foundations}

\section{Uses and Gratifications}

Uses and gratifications theory (U\&G) stresses individual use and choice in communication behaviors and helps explain how the media and their content can be a source of influence within the context of other competing influences (Katz, Blumler, \& Gurevitch, 1974). Several assumptions underlie U\&G. People are active participants who purposively select their media content, influenced by their motivations and past media gratifications. Social and psychological characteristics, societal structure, social groups and relationships, and personal involvement can mediate communication behavior and its effects. Media compete with other channels for selection, attention, and use. Finally, people are more influential than the media in the media effects process. Thus, the two core elements of U\&G are motivations and audience activity (Rubin, 2009).

\section{Motivations.}

Motivations influence not only the selective and active manner in which we seek and use media, but also the subsequent gratifications and possible media effects as people anticipate as well as form expectations about media content. Television U\&G studies have a long and rich tradition (e.g., Ferguson \& Perse, 2000; Rubin, 1981, 1983, 2009; Rubin \& Perse, 1987). So one of our goals is to compare the well-studied motivations for using the traditional medium of TV to those of the much newer online video (specifically, OUSV).

Some U\&G studies have looked at the motivations for new media (e.g., Ferguson \& Perse, 2000; Kaye, 2007). Papacharissi and Rubin (2000) identified five motivations for using the Internet (i.e., e-mail, newsgroups, chatrooms, and browsing): interpersonal utility (e.g., to help others, to meet new people), pass time, information seeking, convenience, and entertainment. Charney and Greenberg (2002) note there is no one standard list of motivations. Their study, which used student responses in 1996 to develop scales using a process similar to that of our study, eventually identified these Internet gratification dimensions: keep informed, diversion-entertainment, peer identity, good feelings, communication, sights and sounds, career, and coolness, with keeping informed, and diversion/entertainment explaining most of the variance. They concluded that "the Internet acts as a one-stop convenience outlet for a variety of different needs that no other single medium can provide" (p. 402). Edwards (2007) suggested that online video combines the instant gratification of TV with the personal control of the Internet.

$\mathrm{RQ}_{1}$ : Motivations and use.

$\mathrm{RQ}_{1 \mathrm{a}}$ : How do U\&G motivations for TV compare to those for online usershared video? 
$\mathrm{RQ}_{1 \mathrm{~b}}$ : How are U\&G motivations associated with TV viewing and with online user-shared video use?

\section{Audience Activity.}

Audience activity refers to the utility, intentionality, selectivity, and involvement of the audience with the media (Levy \& Windahl, 1985; Rubin, 1993, 2009), implying variations in the gratifications viewers receive from media exposure (Rubin \& Perse, 1987). Intentionality includes sharing, recommending, and discussing content with others. Much of the research on audience activity and media orientation has looked at TV viewing (e.g., Levy \& Windahl, 1985). Examples of intentional TV viewing behavior include using program guides to plan TV program viewing (Gantz \& Eastman, 1983), or making plans to watch programs with others (Lemish, 1985). Program selectivity has been operationalized as how often one utilizes various information (i.e., recommendation) sources when deciding which programs to watch (e.g., Perse, 1990).

Sharing information about online content, helping filter and evaluate the vast amount of Web site content, exchanging opinions of it, and providing others with online links to content, represent considerably more ways that one may become exposed to, and engage with, OUSV content than for traditional TV. Generally, users must choose a video sharing site to view, navigate the site for content, and provide at least some ongoing input (e.g., clicking a link, playing a video, reading through descriptions or comments, etc.). The recommendation sources, along with the Web activity the user was engaging in prior to viewing OUSV content (e.g., reading emails, reading a blog, visiting a social networking site), represent and can affect intentionality and selectivity. A feature of many social networking sites (SNS) is the ability to post and share videos and links to videos (see Haridakis \& Hanson, 2009; Madden, 2009; Purcell, 2010; Traffikd, 2011). By 2010, around $50 \%$ of video uploaders used SNS and video-sharing sites (Purcell, 2010). Motivations for watching OUSV may differ from those for sharing those clips (Haridakis \& Hanson, 2009, referring to news videos). Women's intention to share is more influenced by perceived usefulness and by social norms, while men's intention is more influenced by interpersonal norms (Yang, Hsu, \& Tan, 2010).

$\mathrm{RQ}_{2}$ : Audience activity.

$\mathrm{RQ}_{2 \mathrm{a}}$ : Which kinds of online user-shared video recommendation sources are used to find out about online user-shared video content?

$\mathrm{RQ}_{2 \mathrm{~b}}$ : Which kinds of media channels and social relations are used to find out about online user-shared video content?

$R_{2 c}$ : How are online user-shared video recommendation sources, channels, and social relations associated with online user-shared video use? 


\section{Age, Generation, and Contextual Age}

Age.

Media use tends to change with an individual's age (Dimmick, McCain, \& Bolton, 1979). For example, the amount of time adults spend viewing TV increases with age (Harwood, 2007; Nielsen, 2009). Reasons include increased leisure time (either due to retirement or a decline in activities), loss of social contacts (disengagement), lack of mobility, and an increased need for information (Gauntlett \& Hill, 1999; Vandebosch \& Eggermont, 2002). Television use also becomes important among older adults as it offers topics for conversations with others (Davis \& Westbrook, 1985; Riggs, 1998). Further, older adults may have more negative attitudes toward technology, and may not have easy access to, or skills with, computers and the Internet in order to access online video content (Teo, 2001). Cha (2012) reported age differences in the perceived substitutability, and usage of, TV and online video platforms.

\section{Generation.}

Generational theory (Strauss \& Howe, 1991) and Tapscott's (2009) research on the Net Generation offer a different perspective-it is not age per se, but one's generation, that affects media motivations and use. Generations are conceptualized as Silent (born between 1901 and 1924), Gl (1925-1942), Baby Boomers (19461964), Generation X (GenX) (1965-1976), and the Net Generation (1977-1997). Generations may differ with regard to media use because members adopt specific patterns of media use when they are young and have different societal needs for and values about different media use (e.g., Mares \& Woodard, 2006). For example, generations that were young when a particular medium (TV, or the Internet) became popular may have a stronger attachment to it than do previous or later generations. Generation X and the Baby Boomers are often characterized as the "TV Generation" (Strauss \& Howe, 1991), while the Net Generation (also referred to as Generation Y, and the Millennials) grew up during a digital revolution (Tapscott, 2009).

Because younger generations are more familiar with Internet technology, they may be more likely to utilize OUSV for their entertainment. In addition, due to the integration of OUSV with SNS, younger adults are more likely to share this content amongst one another. Older generation members-those in the Silent or GI Generations-may be more likely to turn to TV for information and to pass the time. For older adults who may prefer traditional media to new media forms, and who may have more limited access to OUSV, traditional TV may not be easily replaced. However, for members of the Net Gen, who are used to multitasking, and may not be tied to traditional TV, OUSV may serve as a complement to traditional TV.

\section{Contextual Age.}

Rubin and Rubin (1982) introduced the concept of contextual age, consisting of six dimensions-physical health, economic security, interpersonal interaction, 
mobility, life satisfaction, and social activity-that more fully account for one's media use patterns. Among their sample of older adults, those who were least satisfied with their lives used TV as a means of escape, to forget about their problems, and for companionship. Those who were less mobile used TV as a companion, to forget about their problems, and to learn about new products. Mares and Woodard (2006) found that older adults were more likely to be retired, report poor health, and have fewer interpersonal interactions. However, compared to younger adults, they reported increased economic security, and similar levels of social activity and life satisfaction. Papacharissi and Rubin (2000) found that those who were more mobile, economically secure, satisfied with life, and comfortable with interpersonal interaction preferred more information seeking via the Internet. Conversely, those who were less satisfied with life used the Internet as a functional alternative to interpersonal communication and to pass time. Thus age, generation, and contextual age may all influence one's motivations and use of OUSV slightly differently.

$\mathrm{RQ}_{3}$ : Motivations, Generation, Contextual Age, and Use.

$R_{3 a}$ : How do TV and online user-shared video motivations compare across generations?

$\mathrm{RQ}_{3 \mathrm{~b}}$ : How do TV viewing and online user-shared video use compare across generations?

$\mathrm{RQ}_{3 \mathrm{c}}$ : How do relationships between motivations and viewing/use compare across generations?

$\mathrm{RQ}_{3 \mathrm{~d}}$ : How are contextual age dimensions associated with $\mathrm{TV}$ viewing and online user-shared video use?

$\mathrm{RQ}_{4}$ : Overall Influences on TV Viewing and Online User-shared Video Use. What is the relative influence of demographic characteristics, contextual age dimensions, other media use, and motivations on TV and online usershared video use?

Figure 1 portrays the conceptual relationships underlying the research questions.

\section{Pilot Studies}

Two pilot studies were undertaken in 2007 to identify and evaluate relevant U\&G motivations for viewing TV and online video content, relevant predictors of media adoption and use, and most popular type of online video. First, a pilot survey of 56 U.S. college students responded to 17 items (derived from studies such as Korgaonkar \& Wolin, 1999; LaRose \& Eastin, 2004; Rubin, 1983) which generated five motivation dimensions, and four types of online video content (full episodes, official Web-exclusive, unofficial Web-exclusive, and user-created clips). Second, a sample of 401 college students in the US and Australia were surveyed to find out how TV and Internet use and motivations influenced these four specific types of online video content. With a few changes in items based on principal 


\section{Figure 1}

Model of Influences on TV Viewing and Online User-shared Video Use

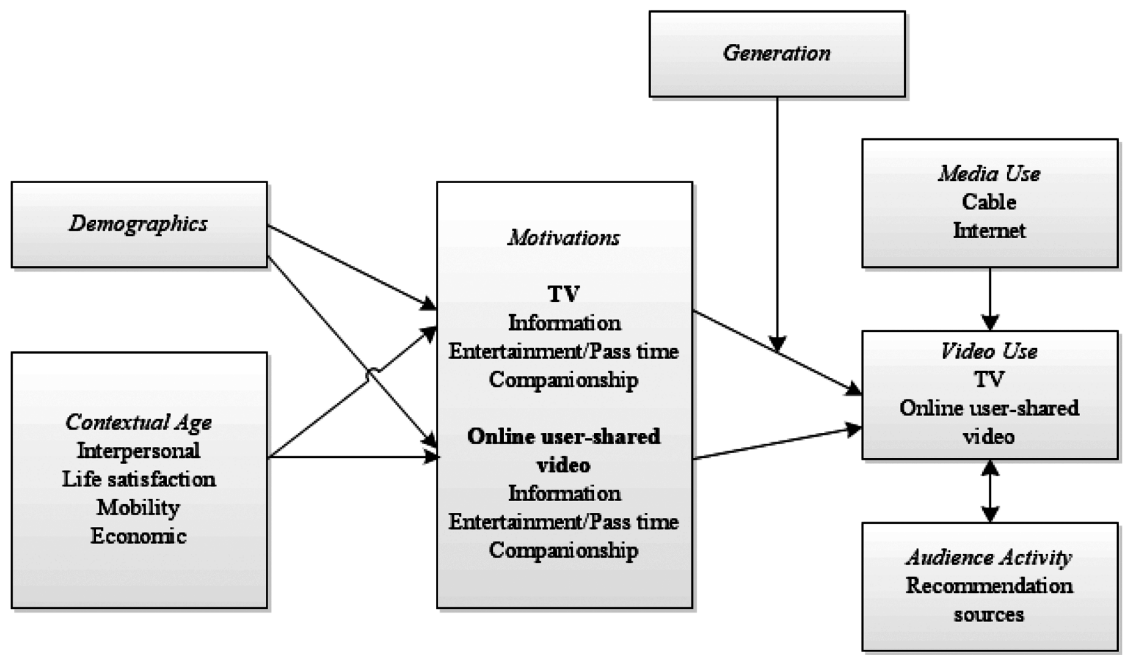

components analyses, the motivation scales exhibited satisfactory reliability. The most popular type was user-generated or professionally produced content Web sites (e.g., YouTube clips). For parsimony, this study compares only TV viewing and OUSV use, defined below.

\section{Full Study: Method}

\section{Sample}

A sample of Americans was surveyed by a professional service ${ }^{1}$ in June 2009. Respondents were part of the service's existing large and continually updated survey panel and were invited by email to participate in exchange for entry into a lottery for a cash prize. Panel participants can choose to participate in any particular survey by clicking the link within 5 days. The survey closes soon after the required/affordable sample size is reached-in this case 500 , with a final usable sample of $\mathrm{N}=511$ so there is no meaningful computed response rate. Comparing the demographics of our sample of around 500 from 2009 with U.S. census data from 2008 (adult Internet users, not all US adults) and Pew Internet data from 2006-2008 (see note to Table 1) shows that the sample is comparable only with regard to gender and representation of white respondents. The sample is more educated and older, and has lower income and percent married. 
Table 1

Descriptive Statistics

\begin{tabular}{|c|c|c|c|c|c|}
\hline \multicolumn{6}{|c|}{ Media Use } \\
\hline \multicolumn{3}{|c|}{ Internet } & \multicolumn{3}{|c|}{ TV and Online Video } \\
\hline $\begin{array}{c}\text { Time Spent } \\
\text { on Average } \\
\text { Day ... }\end{array}$ & $\begin{array}{l}\text { Computer } \\
\text { on } \\
\text { Internet }\end{array}$ & $\begin{array}{l}\text { Mobile } \\
\text { Device on } \\
\text { Internet }\end{array}$ & $\begin{array}{c}\text { How Often } \\
\text { Do You } \\
\text { View ... }\end{array}$ & $\begin{array}{l}\text { Traditional } \\
\text { Television }\end{array}$ & $\begin{array}{c}\text { Online } \\
\text { User-Shared } \\
\text { Video }\end{array}$ \\
\hline None & $.6 \%$ & $52 \%$ & never & $5 \%$ & $43 \%$ \\
\hline$<1 \mathrm{hr}$ & 6 & 23 & once/yr & 3 & 8 \\
\hline $1 \mathrm{hr}$ & 12 & 12 & once/mo & 3 & 14 \\
\hline $2-3 \mathrm{hrs}$ & 37 & 9 & once/week & 5 & 21 \\
\hline 4-5 hrs & 24 & 2 & once/day & 24 & 10 \\
\hline$>=6 \mathrm{hrs}$ & 22 & 3 & several/day & 60 & 5 \\
\hline
\end{tabular}

- Cable or satellite TV: Yes 83\%, No 12\%, Do not watch TV 5\%; Recategorized into Other 0 17\%, Cable/Satellite $183 \%$

- \# years using Internet: $M=10.9$, s.d. $=5.3$

\section{Motivations}

From 17 items, measured as $1=$ strongly disagree to $5=$ strongly agree; scales computed as mean of high-loading items.

Television:

- Information: 4 items, e.g., Helps me learn about others; Learn about how to do things I haven't done before; Learn about things happening the world; Get information for free; $\alpha=.83, M=3.5$, s.d. $=.92$

- Entertainment/Pass time: 5 items, e.g., It entertains me; Something to occupy my time; It's enjoyable; I just like to watch; Passes the time away; $\alpha=.83, \mathrm{M}=$ 3.6, s.d. $=.85$

- Companionship: 2 items, e.g., Because it makes me feel less lonely; $\alpha=.84$, $M=2.3$, s.d. $=1.2$

Online user-shared video:

- Information: 4 items, $\alpha=.95, \mathrm{M}=2.7$, s.d. $=1.2$

- Entertainment/Pass time: 5 items, $\alpha=.94, M=2.9$, s.d. $=1.2$

- Companionship: 2 items, $\alpha=.88, M=1.9$, s.d. $=1.0$ 


\section{Table 1 \\ (Continued)}

Audience Activity: Intentionality and Selectivity

- IF person used online user-shared video (more than once/month) $(\mathrm{N}=288)$ : Sources: SNS 15\%, keyword search $21 \%$, featured/top video $15 \%$, suggested clip $14 \%$, blog $6 \%$, person sent $29 \%$

- IF person sent: Media channels ( $\mathrm{N}=216)$ : email $61 \%$, SNS 19\%, face-to-face $20 \%$

- IF person sent: Social relation ( $\mathrm{N}=212)$ : friend $54 \%$, significant other/spouse $14 \%$, co-worker $8 \%$, relative $23 \%$

Contextual Age

From 15 items; measured from $1=$ strongly disagree to $5=$ strongly agree, scales computed as mean of high-loading items.

- Economic security: 4 items; e.g., I have enough money to buy things I want, even if I don't really need them; $\alpha=.87, M=2.5$, s.d. $=1.1$

- Life satisfaction: 3 items; e.g., compared to other people, I get down in the dumps too often; $\alpha=.79, M=3.3$, s.d. $=1.1$; scale was reversed so that higher values mean more life satisfaction

- Interpersonal interaction: 3 items; e.g., I get to see friends as often as I would like; $\alpha=.56, M=3.2$, s.d. $=.85$

- Mobility: 2 items; e.g., I usually drive my own car or use public transportation to get around; $\alpha=.66, M=4.2$, s.d. $=1.1$

Generation

- NetGen 22\%, GenX 25\%, YoungBoomer 23\%, OldBoomer 18\%, Silent \& GI Generations combined $13 \%$

Demographics

- Gender: male $49 \%$, female $51 \%$

- Age: $M=45.9$, s.d. $=14.1$

- Generations: Gl 1\%, Silent 12\%, Older boomers 18\%, Younger boomers 23\%, Gen X 22\%.

- Marital status: single 29\%, married $49 \%$, separated 3\%, divorced $17 \%$, widowed 3\%

- Race/ethnicity: White, non-Hispanic 79\%, Hispanic/Latino 4\%, African-American 8\%, Asian/Pacific Islander 5\%, Native American 1\%, Other $2 \%$, Decline to state $1 \%$ 


\section{Table 1}

(Continued)

\section{Demographics}

- Education: Less than high school 2\%, High school/GED 24\%, Some college $32 \%$, Associates degree 12\%, Bachelor's degree 15\%, Some graduate school 6\%, Master's degree 9\%, Doctoral degree 1\%, Professional degree (JD, MD) 1\%

- Income: $<\$ 10,00012 \%, \$ 10,001-\$ 19,99910 \%, \$ 20,000-\$ 29,99916 \%$, \$30,000-\$39,999 15\%, \$40,000-\$49,999 11\%, \$50,000-\$59,99911\%, $\$ 60,000-\$ 69,9997 \%$, \$70,000-\$79,999 4\%, \$80,000-\$89,999 4\%, \$90,000$\$ 99,9993 \%, \$ 100,000-\$ 149,9995 \%, \$ 150,000+3 \%$

Comparisons to Adult Internet Access National Samples

This sample was recategorized for comparison:

- Age: 18-34 25\%, 35-54 44\%, 55 + 31\%

- Marital status: married 49\%, single $29 \%$, other $23 \%$

- Education: no college 26\%, attended college $44 \%$, graduated college plus $32 \%$

- Income: <\$50K 64\%, \$50k-\$75K 20\%, \$75K-149K 10\%, \$150K+3\%

U.S. Bureau of the Census (figures as of fall, 2008)

- Gender: male $48 \%$, female $52 \%$;

- Age: 18-34 33\%, 35-54 41\%, 55 + 26\%;

- Marital status: married 55\%, single 26\%, other $16 \%$;

- Education: No college 40\%, attended college 30\%, graduated college plus 30\%

- Income: <\$50K 37\%, \$50K-\$75K 21\%, \$75K-\$149K 31\%, \$150K+12\% Jones and Fox (2009; Pew Internet \& American Life Project; figures aggregated across 2006-2008):

- Gl 4\%, Silent 7\%, Older boomers 13\%, Younger boomers 22\%, Gen X 28\%. $X^{2}$ analyses show that of the demographic variables, only Age does not differ significantly between the sample and the Census Internet users.

Note. $\mathrm{N}=503$ to 511 .

All percentages are rounded to two numbers and thus may not sum to $100 \%$.

\section{Measures}

Table 1 summarizes item wording, response values, descriptive statistics, and alpha reliabilities for each of the following variables.

\section{Media Use.}

Television Use. Respondents indicated how often they watch "traditional television on a television set." Cable/satellite access: Respondents indicated whether and how they viewed TV in their place of residence. 
Computer Internet Use. Respondents indicated how much time during the average day they spend on their computer connected to the Internet; wording specified this includes activities such as checking e-mail, using chat functions, using the www.

Mobile Device Internet Use. Respondents were also asked about Internet use via a mobile device (Horrigan, 2009).

Internet Experience. Respondents indicated how many years they have been using the Internet.

Online User-Shared Video Use. Respondents were asked how often they view "non-professional user-created clips (e.g., funny amateur music videos) or userprovided clips from television (clip from Saturday Night Live) made available on Internet video sharing Web sites (e.g., YouTube)."

Television and Online User-Shared Video Motivations.

The survey included the 17 questions from the pilot studies, asked separately for TV viewing and for OUSV use.

Age, Generation, and Contextual Age.

Age was measured in years since birth. Generation was identified by categorizing the person's year of birth into the generations (NetGen, GenX, Baby Boomers, Silent Generation, and GI Generation). Due to sample sizes, the Silent Generation and the GI Generation were combined, and the Baby Boomers were separated into Young and Old Boomers. Age of course is a strict subset of generation (Spearman rho $=$ .97); however, age is used in overall correlations or regressions, while generation is used to identify mean differences. Contextual age was measured using the 18-item scale developed by Rubin and Rubin (1982).

\section{Audience Activity.}

For those who viewed OUSV content, the survey distinguished between the primary source of the content, and, for the interpersonal source, the channel used for receiving a recommendation, and the social relation with that individual provider. Responses were percentages among the options, with a request to have the percentages sum to $100 \%$.

Content Source. Content source was measured by asking respondents the percent of instances they found out about the OUSV content from each of six content sources.

Channel. If the respondent provided a percent value to the "a person sent the clip or a link to the clip directly to me" content source, they were then asked which channel was used for receiving the recommendation. 
Social Relation. Under the same condition, they were also asked what type of social relation made the recommendation.

\section{Demographic Controls.}

Respondents were asked to indicate their age, gender, marital status, race/ethnicity, highest education level completed, and income level.

\section{Full Study: Results}

Table 2 provides correlations among the central variables.

\section{$\mathrm{RQ}_{1}$ : Motivations and Use}

$R Q_{1 a}$ : How do U\&G motivations for TV compare to those for online user-shared video?

Four TV motivations and three OUSV dimensions, with slight variation in the highloading items, emerged from the two principal components analyses. However, the fourth TV motivation (social interaction; e.g., can be with others who are watching) had only two minimally-loading items, with a low mean scale reliability (.63). So, for parsimony, comparison, and reliability we used the three main, comparable dimensions, with the same items, for each: Information, entertainment/pass time, and companionship. All three motivations were higher for TV $(M=3.5,3.6,2.3)$ than for OUSV $(M=2.7,2.9,1.9$ respectively; paired samples t-tests all significant $p<.001)$.

$R Q_{1 b}$ : How are U\&G motivations associated with TV viewing and with online user-shared video use?

Both TV viewing and OUSV viewing were significantly positively associated with information and with entertainment/pass time, but not with companionship.

\section{$\mathrm{RQ}_{2}$ : Audience Activity}

$R Q_{2 a}$ : Which kinds of online user-shared video recommendation sources are used to find out about online user-shared video content?

With regard to content recommendation sources, OUSV is most frequently discovered from a person directly sending one content links or clips, or by using keywords (29\% and 21\%). Other sources, in decreasing frequency, were SNS (19\%), featured/top video $(15 \%)$, and suggested clip (14\%), with only $6 \%$ via blogs. 
Table 2

Correlations among Viewing/Use, Motivations, and Contextual Age

\begin{tabular}{|c|c|c|c|c|c|c|c|c|c|c|c|}
\hline & 1 & 2 & 3 & 4 & 5 & 6 & 7 & 8 & 9 & 10 & 11 \\
\hline 1. TV viewing & - & & & & & & & & & & \\
\hline 2. TV info & $.21^{* *}$ & - & & & & & & & & & \\
\hline 3. TV ent/pass time & $.32 * *$ & $.49 * *$ & - & & & & & & & & \\
\hline 4. TV comp & .00 & $.28^{* *}$ & $.37^{* *}$ & - & & & & & & & \\
\hline 5. Vid use & .01 & $.17^{* *}$ & $.13^{* *}$ & .06 & - & & & & & & \\
\hline 6. Vid info & -.04 & $.36^{* *}$ & $.23^{* *}$ & $.31^{* *}$ & $.48^{* *}$ & - & & & & & \\
\hline 7. Vid ent/pass time & .00 & $.28^{* *}$ & $.36^{* *}$ & $.27^{* *}$ & $.57^{* *}$ & $.78^{* *}$ & - & & & & \\
\hline 8. Vid comp & $-.13^{* *}$ & $.14^{* *}$ & $.15^{* *}$ & $.54^{* *}$ & .03 & $.52 * *$ & $.45^{* *}$ & - & & & \\
\hline 9. Econ & -.08 & -.08 & $-.17^{* *}$ & .01 & $-.10^{*}$ & .00 & -.07 & .07 & - & & \\
\hline 10. Life sat & -.03 & $-.18^{* *}$ & $-.24^{* *}$ & $-.42^{* *}$ & -.08 & $-.19 * *$ & $-.19 * *$ & $-.28^{* *}$ & $.28^{* *}$ & - & \\
\hline 11. Int interact & .05 & $.18^{* *}$ & $.09 *$ & .03 & -.03 & $.14^{* *}$ & $.10^{*}$ & $.10^{*}$ & $.23^{* *}$ & $.17^{* *}$ & - \\
\hline 12. Mobility & $.16^{* *}$ & 0.04 & 0.08 & $-.16^{* *}$ & -.01 & $-.12^{* *}$ & -.06 & $-.27^{* *}$ & -.04 & $.09 *$ & $.09 *$ \\
\hline
\end{tabular}

Note. ${ }^{*} p<.05 ;{ }^{* *} p<.01$; two-tailed.

$\mathrm{N}=502$ to 510 . 
$R Q_{2 b}$ : Which kinds of media channels and social relations are used to find out about online user-shared video content?

When the content source was a person sending information directly to the user, media channels were primarily email $(61 \%)$, with face-to-face $(20 \%)$ and SNS $(19 \%)$ much lower. The social relation who provided this content link or clip was overwhelmingly a friend $(54 \%)$, much less so a relative $(23 \%)$, and infrequently significant other/spouse (14\%) or co-workers ( $8 \%)$.

$R Q_{2 c}$ : How are online user-shared video recommendation sources, channels, and social relations associated with online user-shared video use?

Using keywords was positively associated $(r=.15, p<.01)$, while having a person send one a clip directly was negatively associated $(r=-.13, p<.05)$, with more OUSV use. Regarding recommendation channels, OUSV use was positively associated with SNS $(r=.19, p<.005)$, and negatively associated with email $(r=-.15, p<.05)$. There were no significant associations among recommendation social relations and frequency of OUSV use. So the source and channel matter a bit (both positively and negatively), but not one's relationship to the recommender.

\section{$\mathrm{RQ}_{3}$ : Motivations, Generation, Contextual Age, and Use}

$R Q_{3 a}:$ How do TV and online user-shared video motivations compare across generations?

A MANOVA was conducted to test for differences in the motivation means across the generations for TV and for OUSV. For TV, the overall difference was significant (Wilks' Lambda $=.95 ; F(12,1328.5)=2.4, p<.01$, though with a partial eta ${ }^{2}$ of only .02). All generations viewed TV for information equally (overall F-test nonsignificant) ( $M=3.5$ to 3.6). There was a very small effect for the entertainment/pass time motivation $(F(4)=2.7, p<.05 ; M=3.6$ to 3.7$)$, but there were no pairwise significant differences. Companionship also differed overall across the generations $(F(4)=6.4, p<.01)$. Post-hoc Scheffe tests showed that the GenX members used traditional TV more for companionship than did the Silent and Gl generation members $(M=2.6$ vs. 2.0). This contradicts other research that suggests older adults view TV to feel less lonely.

There was a slightly larger overall difference across the generations for the OUSV motivations (Wilks' Lambda $=.89 ; F(12,1309.9)=5.0, p<.001$, partial eta ${ }^{2}=.04$ ). For information, NetGen $(M=2.9)$ was significantly higher than Old Boomers $(M=$ 2.3) $(F(4)=3.3, p<.01)$. For entertainment/pass time, NetGen was significantly higher $(M=3.3)$ than Old Boomers $(M=2.4)$, Silent \& $G I(M=2.5)$, and Young Boomers $(M=2.8)$; and GenX $(M=3.0)$ is higher than Old Boomers $(F(4)=9.4$, $p<.001)$. Companionship had the same significant pairwise differences $(F(4)=$ $7.4, p<.001)$. Thus, NetGen respondents had the highest, and Old Boomers the lowest, means across all OUSV motivations. 
$R Q_{3 b}$ : How do TV viewing and online user-shared video use compare across generations?

There was an overall difference across generations (by one-way ANOVA) in level of TV viewing $(F(4,503)=3.1, p<.05)$, increasing with older generations, with NetGen $(M=4.9)$ and Silent/GI $(M=5.5)$ significantly different $(p<.05)$. The overall difference in OUSV use was also significant $(F(4,503)=5.5, p<.001)$, generally increasing with younger generations, with NetGen $(M=2.9)$ and GenX $(M=3.0)$ both significantly higher than Old Boomers $(M=2.1)(p<.01)$.

\section{$R Q_{3 c}$ : How do relationships between motivations and viewing/use compare across generations?}

As Table 3 shows, one's generation plays a moderating role on the relationships between motivations (information and entertainment/pass time) and TV viewing, but not for OUSV use. More specifically, for information motivation, the correlation with TV viewing is significantly higher for the Silent/Gl generation than for GenX. For entertainment/pass time, the correlation is significantly higher for Silent/GI than for NetGen, and higher for both Silent/GI and Young Boomers than for GenX. The companionship correlation is significantly higher for Silent/GI than for NetGen.

$R Q_{3 d}$ : How are contextual age dimensions associated with $T V$ viewing and online user-shared video use?

Four contextual age dimensions (with 15 of the 18 items having sufficiently high loadings; i.e., at least .6, with no loading on other components above .4), emerged from a principal components analysis: Economic security, life satisfaction, interpersonal interaction, and mobility (with the last two having insufficient scale reliabilities). People reported high values for mobility, medium values for life satisfaction and interpersonal interaction, and low levels for economic security (Table 1). Age was positively correlated with all (between $r=.13$ and $.17, p<.01$, two-tailed) except with interpersonal interaction. Greater mobility was slightly associated with more TV viewing $(r=.16, p<.01)$, while lower economic condition was slightly associated with more OUSV use $(r=-.10, p<.05)$ (Table 2).

\section{$R_{4}$ : Overall Influences on TV Viewing and Online User-shared Video Use}

$R_{4}$ : What is the relative influence of demographic characteristics, contextual age dimensions, other media use, and motivations on TV and online user-shared video use?

$\mathrm{RQ}_{1 \mathrm{~b}}$ was assessed through two hierarchical linear regressions, on TV viewing and on OUSV use, explaining $20 \%$ and $45 \%$ variance, respectively (see Table 4 ). 
Table 3

Correlations among Use and Motivations, by Generation

\begin{tabular}{|c|c|c|c|c|c|c|c|c|}
\hline \multirow[b]{2}{*}{$\begin{array}{l}\text { Medium and } \\
\text { Motivations }\end{array}$} & \multicolumn{6}{|c|}{ Generation } & \multirow[b]{2}{*}{$\begin{array}{l}\text { Overall Diff } \\
\text { in Corrs }\end{array}$} & \multirow[b]{2}{*}{ Sign. Diff. Corrs ${ }^{b}$} \\
\hline & Overall & $\begin{array}{c}\text { a. } \\
\text { NetGen }\end{array}$ & $\begin{array}{c}\text { b. } \\
\text { GenX }\end{array}$ & $\begin{array}{c}\text { c. } \\
\text { Young } \\
\text { Boomer }\end{array}$ & $\begin{array}{c}\text { d. } \\
\text { Old } \\
\text { Boomer }\end{array}$ & $\begin{array}{c}\text { e. } \\
\text { Silent } \\
\& \mathrm{Gl}\end{array}$ & & \\
\hline TV Information & $.21^{* *}$ & $.23^{*}$ & .04 & $.25^{* *}$ & .14 & $.46^{* *}$ & $X^{2}=10.1^{*}$ & $a b^{*} a e^{*} b c^{*} b e^{* *} c e^{*} d e^{*}$ \\
\hline $\begin{array}{l}\text { Entertainment/ } \\
\text { Pass time }\end{array}$ & $.32^{* *}$ & $.36^{* * *}$ & .14 & $.47^{* *}$ & $.24^{* *}$ & $.65^{* *}$ & $X^{2}=20.8^{* * *}$ & $a b^{*} a e^{* *} b c^{* *} b e^{* *}$ \\
\hline Companionship & .00 & -.11 & -.05 & .03 & .10 & $.30^{* *}$ & $X^{2}=8.4$ n.s. & be* $\mathrm{ce}^{*}$ \\
\hline $\mathrm{N}$ & 510 & 111 & 127 & 116 & 89 & 65 & & \\
\hline \multicolumn{9}{|c|}{$\begin{array}{l}\text { Online user-shared } \\
\text { video }\end{array}$} \\
\hline Information & $.48^{* *}$ & $.38^{* *}$ & $.46^{* *}$ & $.56^{* *}$ & $.48^{* *}$ & $.51^{* *}$ & - & - \\
\hline $\begin{array}{l}\text { Entertainment/ } \\
\text { Pass time }\end{array}$ & $.57^{* *}$ & $.49^{* *}$ & $.59 * *$ & $.59 * *$ & $.52 * *$ & $.58^{* *}$ & - & - \\
\hline Companionship & .03 & .03 & .06 & -.07 & -.09 & -.10 & - & - \\
\hline $\mathrm{N}$ & 503 & 111 & 125 & 114 & 89 & 64 & & \\
\hline
\end{tabular}


Table 4

Influences on Television Viewing and Online User-shared Video Use

\begin{tabular}{|c|c|c|}
\hline & $\begin{array}{l}\text { Television } \\
\text { Viewing }\end{array}$ & $\begin{array}{c}\text { Online User-Shared } \\
\text { Video Use }\end{array}$ \\
\hline Age & $.15^{* * *}$ & $-.07 *$ \\
\hline Education & .06 & .08 \\
\hline Income & -.00 & -.08 \\
\hline Gender $(M=1)$ & -.04 & .05 \\
\hline Status (Married $=1$ ) & .04 & -.01 \\
\hline Race $($ White $=1)$ & .04 & $-.11^{* *}$ \\
\hline Adj. $R^{2}$ & $.03^{* * *}$ & $.05^{* * *}$ \\
\hline Economic & -.07 & -.04 \\
\hline Life satisfaction & -.05 & .01 \\
\hline Interpersonal interaction & -.01 & -.05 \\
\hline Mobility & $.09 *$ & -.06 \\
\hline Adj. $R^{2}$ & $.05^{* *}$ & $.07^{*}$ \\
\hline Cable/sat $(\mathrm{N}=0 \mathrm{Y}=1)$ & $.24^{* * *}$ & -.01 \\
\hline TV viewing & - & -.01 \\
\hline Computer Internet use & $.09 *$ & $.12^{* * *}$ \\
\hline Years using Internet & -.03 & -.04 \\
\hline Adj. $R^{2}$ & $.14^{* * *}$ & $.11^{* * *}$ \\
\hline Information & .03 & $.21^{* *}$ \\
\hline Entertainment/Pass time & $.28^{* * *}$ & $-.52 * * *$ \\
\hline Companionship & $-.09 *$ & $-.33^{* * *}$ \\
\hline $\mathrm{N}$ & 486 & 478 \\
\hline F-ratio & $18.4^{* * *}$ & $58.8^{* * *}$ \\
\hline Adj. $R^{2}$ & .20 & .45 \\
\hline
\end{tabular}

${ }^{*} p<.05 ;{ }^{* *} p<.01 ;{ }^{* * *} p<.001$.

Note. Hierarchical linear regression with stepwise entry within blocks. Values are standardized beta coefficients. Adj. $\mathrm{R}^{2}$ values for interim blocks are cumulative, with significance of $\mathrm{F}$ change between blocks.

Significant influences for television viewing were greater age, greater mobility, cable/satellite access, greater computer-based Internet use, greater entertainment/pass time motivation, and less companionship motivation. Significant influences on online user-shared video use included being younger and non-white, greater computer Internet use, and greater information motivation, but less entertainment/pass time and companionship motivations. Note the differential roles of motivations for the two media. 


\section{Discussion}

\section{Main Insights}

Uses and gratifications theory continues to be useful in providing some distinctions among media forms, and in helping differentially to explain usage of traditional and new media. For example, motivations are lower overall for OUSV usage than for TV viewing, indicating either a still-nascent development of traditional media motivations, or a newly emerging media form that may not fulfill traditional ones as well; indeed, respondents assess all their motivations for OUSV as neutral or somewhat negative.

Entertainment is the primary motivation for TV viewing, but respondents disagree that this motivates their OUSV usage. Online user-shared video use is motivated by more instrumental (informational) purposes, unlike traditional TV. Yet, even more than TV, it is not sought for companionship purposes, in spite of the social features of user-shared video sites and the associated recommendation processes. On the basis of these three central motivations alone, we can see that these are quite different media. (As noted, there was a weak and insufficiently reliable 4th TV motivations dimension of social interaction, and it was negatively associated with TV viewing. So the traditional U\&G motivation of social interaction still plays a role in TV viewing, but does not emerge as a separate motivation for, and thus an influence on, OUSV.)

This study also helps shed light on how users find out about OUSV content. Although most OUSV content is discovered from a social relation directly sharing clips or links to clips, these recommendations were not associated with greater use. Discovering content using keyword searching was related to increased use. Thus, greater OUSV use is positively associated with more intentional and selective audience activity, such as using keywords or SNS, and negatively with more passive activity, such as receiving a clip from someone or getting the recommendation via email. Or large video clips are perceived as "spam" or "pushed" content and reduce one's online video use satisfaction. Another interpretation is that less frequent users do not have sufficient skills to actively seek out such content. While friends may be the primary sources of these recommendations, and SNS are heavily associated with concepts of social networks and "friends," the social relation type of recommender is independent of one's OUSV use.

Demographics played a minimal role in explaining either TV viewing or OUSV use. Contextual age fared little better, with only greater mobility remaining an influence in only the TV viewing regression. Generation moderates some relationships between motivations and TV viewing (especially for Silent/GI compared to GenX), but has no moderating effect on the relationships for OUSV (Table 3).

\section{Limitations}

Because this is a cross-sectional study asking for perceptions of motivations after considerable use of the two media (in most cases), this study cannot determine 
whether initial motivations differ from subsequent gratifications, which in turn may affect subsequent perceptions of motivations and of differential media use. While we sought a nationally representative sample, this is not representative for several demographics.

Concerning the definition of online user-shared video, certainly online viewing has changed even in the few years since the data were collected in 2009. For example, there is vastly more content via paid subscription in Hulu Plus beginning in 2010 and on sites like YouTube (YouTube, 2011). Also, the greater popularity of devices capable of streaming video content (video game consoles and stand-alone players like Roku) will have increased such viewing. While this study focused on shorter video content, there is a move toward longer form online video viewing such as full films on Netflix or Hulu. ${ }^{2}$ Further, content providers are moving toward more social online video viewing, such MTV's WatchWith ${ }^{3}$ which it calls a "DVR for social commentary," or gamified social viewing like GetGlue, ${ }^{4}$ a social networking site for consuming content (where one "checks in" as watching, e.g., Game of Thrones to earn badges). Thus, what it means to be social with regard to online video viewing is undergoing constant change.

Additionally, this study did not explicitly ask about pirated video because in our pilot test, very few participants reported downloading video content via illegal means (though one can question the validity of such questions and such answers). However, certainly methods of obtaining pirated videos like peer-to-peer BitTorrent are popular, with 150 million global users in $2012 .^{5}$ In $2009,43-70 \%$ of global Internet traffic was BitTorrent ${ }^{6}$ (although not all BitTorrented files are illegal). BitTorrent at any given time has more active users than NetFlix, Hulu, YouTube, and Facebook combined (ComScore, 2010). ${ }^{7}$ Online pornography is also a major type of online video (e.g., XTube), and does include user-created content, but, for understandable reasons, was neither asked about nor mentioned in our studies (but see Paul \& Shim, 2008).

The sample is relatively small, but generally representative of the US. Two of the 11 scales (both contextual age) have reliabilities below the minimum of .70. This is unfortunate, given that they are based on prior literature and research. So some scale improvement may be necessary. Further, there are of course many other influences on OUSV viewing, such as industrial setting, services available, cost, ease of use, image quality, recommendation systems, and platform (Strover \& Moner, 2012).

\section{Future Research}

To the extent new media provide similar or improved media experience and content, and thus invoke different motivations, they may substitute for/be functionally equivalent to, or instead complement/augment, more traditional media (Katz et al., 1974; Lin, 2004). There is extensive commercial and academic research on this issue, such as the effect of online newsreading or entertainment consumption on the finances and forms of print news and TV programs (e.g., Nakashima, 2011; Stelter, 2012). Such effects and changes may occur as a functional alternative or 
through time shifting, or by simply adding to the time already spent watching TV by meeting somewhat different needs, such as information, in different styles, such as multitasking. In the current study, if we ignore generational differences, we would find no relationship between TV viewing and OUSV use (Table 2, $r=.01$; and a non-significant role in the regression, Table 4), and thus conclude that the use of these two media is completely independent (neither functionally equivalent, nor complementary). However, there is some support for the argument that for generations that have "embraced" traditional TV (Young Boomers), OUSV use will slightly substitute (be a functional alternative) for time spent viewing the TV set $(r=-.07, p<.05)$. Further, those growing up with digital media (GenX) may complement TV viewing with OUSV use $(r=.27, p<.05)$, such as through online clips from one's favorite shows, or additional content associated with a program. Research in this area should also explore whether different types of online viewing affect different types of TV viewing.

Future studies should continue to look at the role of SNS and other multimedia Web sites in media sharing and viewing, especially as these sites allow users to upload and access many types of content simultaneously (e.g., videos, photos, music, comments). This may also have implications on what constitutes intentionality. For instance, although users can view videos, post comments, and send messages to friends within an SNS, they may not consider these different forms of communication. Their intention may be to visit a SNS, but they are nonetheless essentially communicating in various ways with others.

Overall, the basic U\&G motivations also apply to the new online media world, but have different levels, influences, and outcomes. The series of studies indicated three traditional motivations were relevant here (information, entertainment/pass time, and companionship), and that the two media differ with respect to the first two. Though we began with a broad list of possible U\&G motivations, based on prior research, it may be that non-traditional U\&G motivations are emerging with online video use in general, so qualitative research may be useful in exploring such a possible extension of U\&G motivations. Generation (a moderating influence), contextual age (a slight direct influence), and recommendation sources (a direct influence) play additional roles not much included in prior U\&G studies of new media use. Thus uses and gratifications research should continue to assess these more subtle influences in the online and digital media environment.

\section{Notes}

\footnotetext{
${ }^{1}$ Survey Sampling International, http://surveysampling.com

${ }^{2}$ http://www.comscore.com/Press_Events/Presentations_Whitepapers/2012/2012_US_ Digital_Future_in_Focus

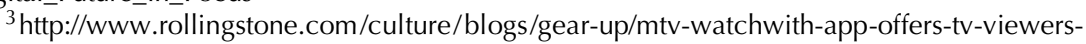
odd-company-20110823

${ }^{4}$ http://en.wikipedia.org/wiki/GetGlue

${ }^{5}$ http://www.bittorrent.com/intl/es/company/about/ces_2012_150m_users
} 

.pdf

${ }^{6}$ http://www.ipoque.com/sites/default/files/mediafiles/documents/internet-study-2008-2009

${ }^{7} \mathrm{http} / / / w w w . f a s t c o m p a n y . c o m / 1714001 /$ bittorrent-swells-to-100-million-users and http:// www.comscore.com/Press_Events/Press_Releases/2010/9/comScore_Releases_August_2010_ U.S._Online_Video_Rankings

${ }^{8}$ http://luna.cas.usf.edu/ mbrannic/files/regression/corr1.html\#More than two

${ }^{9} \mathrm{http}: / /$ faculty.vassar.edu/lowry/rdiff.html

\section{References}

Cha, J. (2012). Substitutability between online video platforms and television. Journalism and Mass Communication Quarterly, 89(2), 261-278.

Charney, T., \& Greenberg, B. (2002). Uses and gratifications of the Internet. In C. Lin \& D. Atkin (Eds.), Communication technology and society: Audience adoption and uses of the new media (pp. 379-407). Cresskill, NJ: Hampton Press.

Chorianopoulos, K., \& Lekakos, G. (2008). Introduction to social TV: Enhancing the shared experience with interactive TV. International Journal of Human-Computer Interaction 24(2), 113-120. doi: 10.1080/10447310701821574

comScore. (2010). U.S. online video market continues ascent as Americans watch 33 billion videos in December. Retrieved October 22, 2011 from http://www.comscore.com/Press_ Events/Press_Releases/2010/2/U.S._Online_Video_Market_Continues_Ascent_as_Ameri cans_Watch_33_Billion_Videos_in_December

Davis, R. H., \& Westbrook, G. J. (1985). Television in the lives of the elderly: Attitudes and opinions. Journal of Broadcasting and Electronic Media, 29, 209-214.

Dimmick, J. W., McCain, T. A., \& Bolton, W. T. (1979). Media use and the life span: Notes on theory and method. American Behavioral Scientist, 23, 7-31. doi: 10.1177/000276427 902300102

Edwards, C. (2007). I want my iTV. Business Week, November 19, 54-64.

Ferguson, D. A., \& Perse, E. M. (2000). The World Wide Web as a functional alternative to television. Journal of Broadcasting and Electronic Media, 44, 155-174. doi: 10.1207/s1550 6878jobem4402_1

Fox, S. (2010, January 13). Four in ten seniors go online. http://www.pewinternet.org/Commen tary/2010/January/38-of-adults-age-65-go-online.aspx

Gantz, W., \& Eastman, S. T. (1983). Viewer uses of promotional media to find out about television programs. Journal of Broadcasting, 27, 269-277.

Gauntlett, D., \& Hill, A. (1999). TV living: Television, culture and everyday life. New York, NY: Routledge.

Haridakis, P., \& Hanson, G. (2009). Social interaction and co-viewing with YouTube: Blending mass communication reception and social connection. Journal of Broadcasting \& Electronic Media, 53(2), 317-335. doi: 10.1080/08838150902908270.

Harwood, J. (2007). Understanding communication and aging: Developing knowledge and awareness. Thousand Oaks, CA: Sage Publications.

Held, G. (2007). Understanding IPTV. Boca Raton, FL: Auerbach Publications.

Horrigan, J. (2009, June 17). Home broadband adoption 2009. http://www.pewinternet.org/ Reports/2009/10-Home-Broadband-

Jenkins, H. (2006). Convergence culture: Where old and new media collide. New York, NY: New York University Press.

Jones, S., \& Fox, S. (2009). Generational differences in online activities. Washington, DC: Pew Internet \& American Life Project. http://www.pewinternet.org/Reports/2009/GenerationsOnline-in-2009/Generational-Differences-in-Online-Activities/2-Internet-use-and-email . aspx 
Katz, E., Blumler, J. G. \& Gurevitch, M. (1974). Uses and gratifications research. In J. G. Blumler, \& E. Katz (Eds.), The uses of mass communications (pp. 19-32). Beverly Hills, CA: Sage.

Kaye, B. K. (2007). Blog use motivations: An exploratory study. In M. Tremayne (Ed.), Blogging, citizenship, and the future of media (pp. 127-147). New York, NY: Routledge.

Klar, J. (January 7, 2011). Stewart, Colbert, and Hulu's thoughts about the future of TV. http://blog.hulu.com/2011/02/02/stewart-colbert-and-hulus-thoughts-about-the-future-of-tv/ [Klar is Hulu CEO.]

Korgaonkar, P. K., \& Wolin, L. D. (1999). A multivariate analysis of Web usage. Journal of Advertising Research, 39, 53-68.

LaRose, R., \& Eastin, M. S. (2004). A social cognitive theory of Internet uses and gratifications: Toward a new model of media attendance. Journal of Broadcasting and Electronic Media, 48, 358-377. doi: 10.1207/s15506878jobem4803_2

Lemish, D. (1985). Soap opera viewing in college: A naturalistic inquiry. Journal of Broadcasting \& Electronic Media, 29, 275-293. doi: 10.1080/08838158509386585

Levy, M. R., \& Windahl, S. (1985). The concept of audience activity. In K. E. Rosengren, L. A. Wenner, \& P. Palmgreen (Eds.), Media gratifications research: Current perspectives on gratifications research (pp. 109-122). Beverly Hills, CA: Sage Publications.

Lin, C. A. (2004). Webcasting adoption: Technology fluidity, user innovativeness, and media substitution. Journal of Broadcasting \& Electronic Media, 48, 446-465.

Madden, M. (2009). The audience for online video-sharing sites shoots up. Pew Internet \& American Life Project. http://fe01.pewinternet.org/Reports/2009/13-The-Audience-for-On line-VideoSharing-Sites-Shoots-Up.aspx

Mares, M. L., \& Woodard, E. H. (2006). In search of the older audience: Adult age differences in television viewing. Journal of Broadcasting \& Electronic Media, 50, 595-614. doi: 10. 1207/s15506878jobem5004_2

Meng, X-L., Rosenthal, R., \& Rubin, D. B. (1992). Comparing correlated correlation coefficients. Psychological Bulletin, 111, 172-175. doi: 10.1016/j.meegid.2004.01.007

Moore, K. (2011, July 25). 71\% of online adults now use video-sharing sites. Pew Internet \& American Life Project. http://pewInternet.org/ /media//Files/Reports/2011/Video\% 20sharing\%202011.pdf

Nakashima, R. (2011, June 15). Online video viewers watch less TV: Nielsen study. Retrieved October 22, 2011 from http://www.huffingtonpost.com/2011/06/15/online-video-viewerswatc_n_877674.html

The Nielsen Company. (2009, April 22). Online engagement deepens as social media and video sites reshape the Internet, Nielsen reports [Press release]. http://blog.nielsen.com/ nielsenwire/wp-content/uploads/2009/04/nielsen-online-global-_pr.pdf

Noam, E., Groebel, J., \& Gerbarg, D. (Eds.) (2004). Internet television. Mahwah, NJ: Lawrence Erlbaum.

Papacharissi, Z., \& Rubin, A. M. (2000). Predictors of Internet use. Journal of Broadcasting \& Electronic Media, 44, 175-196. doi: 10.1207/s15506878jobem4402_2

Paul, B., \& Shim, J. W. (2008). Gender, sexual affect, and motivations for Internet pornography use. International Journal of Sexual Health, 20(3), 187-199.

Perse, E. M. (1990). Audience selectivity and involvement in the newer media environment. Communication Research, 17, 675-697. doi: 10.1177/009365090017005005

Pew Internet \& American Life Project (n.d.). Usage over time. Spreadsheet. Washington, DC: Pew Internet \& American Life Project. http://www.pewinternet.org/Trend-Data/UsageOver-Time.aspx

Purcell, K. (2010, June 3). The state of online video. Pew Internet \& American Life Project. http://pewinternet.org/Reports/2010/State-of-Online-Video.asp

Rice, R. E. (Ed.) (2008). Media ownership: Research and regulation. Cresskill, NJ: Hampton Press.

Riggs, K. E. (1998). Mature audiences: Television in the lives of the elderly. New Brunswick, NJ: Rutgers University Press. 
Rubin, A. M. (1981). An examination of television viewing motivations. Communication Research, 8, 141-165. doi: 10.1177/009365028100800201

Rubin, A. M. (1983). Television uses and gratifications: The interactions of viewing patterns and motivations. Journal of Broadcasting, 71, 37-51. doi: 10.1080/08838158309386471

Rubin, A. M. (1993). Audience activity and media use. Communication Monographs, 60, 98105. doi: 10.1080/03637759309376300

Rubin, A. M. (2009). The uses-and-gratifications perspective of media effects. In J. Bryant, \& M. B. Oliver (Eds.), Media effects: Advances in theory and research (pp. 165-184). New York, NY: Routledge.

Rubin A. M., \& Perse, E. M. (1987). Audience activity and television news gratifications. Communication Research, 14, 58-84. doi: 10.1177/009365087014001004

Rubin, A. M., \& Rubin, R. B. (1982). Contextual age and television use. Human Communication Research, 8, 228-244. doi: 10.1111/j.1468-2958.1982.tb00666.x

Shirky, C. (2008). Here comes everybody: The power of organizing without organizations. New York, NY: Penguin Press.

Spigel, L., \& Olsson, J. (Eds.) (2004). Television after TV: Essays on a medium in transition. Durham, NC: Duke University Press.

Stelter, B. (2012). Youths are watching, but less often on TV. The New York Times, February 8. http://www.nytimes.com/2012/02/09/business/media/young-people-are-watching-but-lessoften-on-tv.html

Strauss, W., \& Howe, N. (1991). Generations: The history of America's future, 1584 to 2069. New York, NY: William Morrow and Co.

Strover, S., \& Moner, W. (2012, May). Immersive television and the on-demand audience. Paper presented to International Communication Association Conference, Phoenix, AZ.

Tapscott, D. (2009). Growing up digital: How the Net Generation is changing your world. New York, NY: McGraw-Hill.

Teo, T. (2001). Demographic and motivation variables associated with Internet usage activities. Internet Research-Electronic Networking Applications and Policy, 11, 125-137. doi: $10.1108 / 10662240110695089$

Traffikd. (2011). List of social media and social networking sites. Retrieved Oct. 22, 2011 from http://traffikd.com/social-media-websites/

U.S. Bureau of the Census. (2008). Information and communications: Table 1120: Internet access and usage. Statistical abstract of the United States. Washington, D.C. http://www. census.gov/prod/2009pubs/10statab/infocomm.pdf

Vandebosch, H., \& Eggermont, S. (2002). Elderly people's media use: At the crossroads of personal and societal developments. Communications, 27, 437-455. doi: 10.1515/comm. 2002.002

Weber, R. (2007). To adjust or not to adjust alpha in multiple testing: That is the question. Guidelines for alpha adjustment as response to O'Keefe's and Matsunaga's critiques. Communication Methods and Measures, 1, 281-289. doi: 10.1080/19312450701641391

Yang, C., Hsu, Y-C., \& Tan, S. (2010). Predicting the determinants of users' intentions for using YouTube to share video: Moderating gender effects. Cyberpsychology, Behavior, and Social Networking, 13(2), 141-152. doi: 10.1089/cyber.2009.0105

YouTube. (2011, October 28). More great content creators coming to YouTube. Retrieved Oct. 28, 2011 from Broadcasting ourselves-The official YouTube blog. http://youtubeglobal.blogspot.com/2011/10/more-great-content-creators-coming-to.html 